\#8221 Supporting information of the manuscript entitled:

\title{
Biomolecular interaction monitoring of autoantibodies by scanning SPR microarray imaging
}

\author{
Angelique M.C.Lokate ${ }^{2}$, J. Bianca Beusink ${ }^{1}$, Geert A.J. Besselink ${ }^{1}$, Ger J.M. Pruijn ${ }^{2}$, and \\ Richard B.M. Schasfoort $*^{1}$ \\ 1 Biochip Group, MESA+ Research Institute for Nanotechnology, University of Twente, PO Box 217, NL-7500 AE Enschede, \\ The Netherlands \\ 2 Department of Biomolecular Chemistry, Nijmegen Centre for Molecular Life Sciences, Institute for Molecules and \\ Materials, Radboud University Nijmegen, PO Box 9101, NL-6500 HB Nijmegen, The Netherlands \\ E-mail address corresponding author: R.B.M.Schasfoort@ @nw.utwente.nl
}

\#8220 The complete reference 11 is enclosed:

Robinson,W.H.; DiGennaro,C.; Hueber,W.; Haab,B.B.; Kamachi,M.; Dean,E.J.; Fournel,S.; Fong,D.; Genovese,M.C.; Neuman de Vegvar,H.E.; Skriner,K.; Hirschberg,D.L.; Morris,R.I.; Muller,S.; Pruijn,G.J.; Van Venrooij,W.J.; Smolen,J.S.; Brown,P.O.; Steinman,L.; Utz,P.J. Nat. Med. 2002, 8, 295-301.

\#8221; Movie of the scanning SPR imaging principle. Every point of a sensorgram is obtained from the scanning angle process by calculating the minimum of reflectance of a region of interest from a spot of the microarray. The minimum of reflectance of various spots are at different SPR angles and accurately determined using high speed imaging processing techniques. 